\title{
A música nas aulas de história: 0 debate teórico sobre as metodologias de ensino
}

\author{
Music in history classes: the theoretical \\ debate on teaching methodologies
}

Olavo Pereira Soares*

\section{Resumo}

Este artigo analisa concepções metodológicas diferentes acerca da utilização da música nas práticas de ensino de história. Inicialmente, analisamos as metodologias que propõem a utilização da música como recurso didático, mas que desestimulam os alunos a aprenderem história. Posteriormente, discorremos sobre a necessidade de valorização, nas práticas de ensino, das relações afetivas que os alunos têm com a música, bem como sobre a necessidade de conhecer a cultura musical dos alunos. Por fim, defendemos uma proposta metodológica de utilização das músicas nas aulas de história que considere a cultura musical dos alunos, bem como as capacidades cognitivas de professores e alunos para produzir conhecimento histórico a partir da análise de músicas elaboradas e difundidas em diferentes tempos e espaços. Palavras-chave: música no ensino; ensino de história; atividade de ensino.

\section{Abstract}

This paper analyses different methodological conceptions about the use of music in history teaching practices. Initially, it is analysed the methodologies that propose the use of music as a teaching resource, but that discourage students to learn history. Afterwards, we discuss the appreciation necessity of the affective relationships that students have with the music in educational practices, as well as the need to know the students musical culture. Finally, we advocate a methodological proposal for the use of music in history classes to consider the musical culture of the students, as well as cognitive skills that teachers and students have to produce historical knowledge from the analysis of elaborated and disseminated music at different times and spaces.

Keywords: music in teaching; History teaching; teaching activity.

\footnotetext{
* Doutor em Educação (USP). Professor Adjunto do Instituto de Ciências Humanas e Letras da Universidade Federal de Alfenas (Unifal-MG) e Professor do Programa de Pós-Graduação em Educação (PPGE/Unifal-MG). Alfenas, MG, Brasil. olavopereirasoares@gmail.com
} 
No Brasil, ensinar história é sempre uma tarefa difícil. Aqui, o passado é sinônimo de velharia, e velharia é algo a ser descartado. Poucas são as cidades em que há preocupação com o Patrimônio Histórico, e normalmente o que se vê é o oposto: casas, igrejas e construções "velhas" sendo demolidas. Em nossas práticas escolares verificamos que os alunos, com algumas exceções, não têm a percepção do passado na sua prática cotidiana: não utilizam nem interagem com objetos antigos, não identificam construções do passado, não conversam com os membros mais velhos das famílias ou vizinhos. Ironicamente, a novidade que extingue o passado do cotidiano vivido proporciona às crianças e adolescentes uma cultura midiática que os remete a todo instante ao passado não vivido por meio dos filmes, minisséries, documentários, videoclipes e músicas.

Em função desse contexto é que defendemos neste artigo que os professores de história precisam estar cotidianamente atentos às metodologias de ensino. Ter conhecimento historiográfico é fundamental, pois ninguém ensina algo sobre o qual não tem conhecimento. Mas um ensino de história que desconsidere a realidade vivida e os contextos sociais e históricos dos quais os alunos são sujeitos está fadado ao fracasso, pois não podemos desconsiderar que a maioria de nossos alunos interage com esse cenário contraditório, no qual o passado é socialmente desprestigiado, mas midiaticamente difundido. Portanto, é preciso se dedicar aos estudos sobre as metodologias de ensino que, considerando a realidade vivida, viabilizam a produção do conhecimento histórico em ambiente escolar.

Nesse sentido, a análise das relações entre música e ensino de história é fundamental por duas razões básicas: porque as músicas têm importância significativa na cultura cotidiana dos alunos, e porque o professor de história pode encontrar na música um aliado, um recurso didático dos mais importantes, que cria empatia com os alunos.

Para a análise da temática, nos referenciamos teoricamente nos fundamentos da perspectiva histórico-cultural, notadamente nos trabalhos de Lev S. Vigotski e Alexei Leontiev, e apresentamos a análise de dados de pesquisa realizada sobre processos de leitura e escrita no ensino de história. ${ }^{1} \mathrm{O}$ artigo está dividido em três momentos de análise: sobre as situações nas quais a música é utilizada para ensinar, mas desestimula os alunos a aprenderem história; sobre a importância de se compreender as interações afetivas que os alunos 
têm com a música e as implicações para a sua utilização nas aulas de história; e, finalmente, sobre as situações em que as interações afetivas dos alunos com as músicas são valorizadas nos processos de ensino e suas implicações nas aprendizagens e na produção do conhecimento histórico escolar.

\section{MÚSICA PARA DESISTIR DA HISTÓRIA... OU... "VALEI-ME DEUS, É O FIM DO NOSSO AMOR..."}

Certa tarde, em reunião do Grupo de Pesquisa do qual participo, ${ }^{2}$ uma colega se lembrou de uma atividade relacionada às aulas de história de sua infância. Era uma música que os alunos tinham de decorar para aprender a matéria. O surpreendente é que, tantos anos passados, ela cantou a música sem pestanejar, ou seja, havia decorado mesmo.

A música é sobre o "descobrimento do Brasil", e a versão que a colega me mostrou tem esta letra:

Dom Manuel, 'O Venturoso'/ era rei de Portugal/ escolheu para ir às Índias/ Pedro Álvares Cabral./ Navegou até que um dia/ novas terras avistou/ E num porto com alegria/ Bem seguro ele ancorou./ Ai, ai, ai, era 22 de abril./ Que Cabral aqui chegando/ descobriu o meu Brasil!/ Frei Henrique de Coimbral Duas missas celebrou/ Logo Pero Vaz Caminha/ Uma carta ao rei mandou./ Pra falar das novas terras/ Descobertas por Cabral/ E logo delas tomou posse/ Para o rei de Portugal./ Ai, ai, ai, rica terra tão gentil/Vera Cruz e Santa Cruz/ Têm hoje o nome de Brasil!

Depois de receber esta versão, procurei na internet se havia algum registro sonoro da música e nada encontrei. No entanto, há um blog em que a letra é divulgada, até mesmo com alguns acréscimos que incluem uma citação a "Tiradentes". ${ }^{3}$ O blog reforça o relato da colega de que a música era muito difundida, quiçá ainda seja, pelas práticas de ensino de história das séries iniciais de muitas escolas do interior de São Paulo.

É importante destacar o esforço dos professores em transformar a história em algo inteligível aos alunos, e concomitantemente responder aos anseios socialmente veiculados de que a história deve ensinar os "valores da pátria". 
Nos exemplos citados, parece-nos que os professores se utilizavam da música como recurso didático, a fim de atingir esses dois objetivos.

Podemos inferir também que tais professores estão preocupados com um bom ensino. No entanto, é preciso perguntar: o que os alunos aprendem quando os professores se utilizam da música dessa forma?

Aprendem muitas coisas, mas na contramão tanto da historiografia quanto das pesquisas sobre ensino de história: aprendem que a história é feita de heróis e personagens que residem no passado. Os alunos também podem aprender a escrever corretamente algumas palavras, aprender a soletrar, podem até aprender um pouco de melodia. Mas ao decorar a letra e cantarolar, provavelmente não aprenderam sobre o fato de que fazemos parte da história, pois somos sujeitos dela e capazes de produzir conhecimento sobre ela.

Consideremos então que, nesse caso, a utilização da música enquanto recurso didático mais desestimula o aprendizado da história do que o oposto.

Há dois motivos bem objetivos para fazermos essa afirmação: o primeiro está relacionado ao conteúdo em si; o segundo, ao método.

Em termos de currículo e de conhecimento histórico a ser trabalhado nas séries iniciais, há quase um consenso entre pesquisadores do ensino de história de que os conteúdos voltados para a formação da pátria e do cidadão patriótico estavam vinculados a momentos específicos de nossa história política e não têm vínculos com a produção historiográfica. Desde as propostas curriculares do final dos anos 1980 tais concepções são consideradas equivocadas (Fonseca, 2003), notadamente no que se refere ao ensino de história para crianças. Nos anos 1990, os PCNs (Brasil, 1998) selaram a opção por um ensino de história que aproxime crianças e adolescentes do fazer historiográfico, bem como instituiu uma concepção diversa sobre a cidadania.

Em termos metodológicos, algumas dessas concepções sobre a utilização da música nas aulas de história permanecem nas ações didáticas de professores, e não apenas daqueles que dão aulas nas séries iniciais, mas também dos professores especialistas que atuam no ensino fundamental II e ensino médio. São concepções metodológicas que compreendem a música como um recurso didático que auxilia os professores a pedirem a atenção dos alunos, que facilitam os processos de memorização de determinadas informações, ou servem de "apêndice" para as aulas e demais atividades escolares. 
Embora possa parecer óbvio que por meio da memorização de uma música não se ensina sobre a história e sobre o fazer historiográfico, esse exemplo de metodologia de ensino que não possibilita a aprendizagem precisa ser teoricamente analisado.

Um dos teóricos que nos auxilia nessa análise é Alexei Leontiev (1978). Segundo esse pesquisador uma atividade didática ${ }^{4}$ e os recursos nela utilizados devem ter estreita relação com o objeto de estudo da atividade. Nesse caso, a atividade de ler, decorar e cantar uma música em nada se relaciona com o objeto de estudo e de conhecimento da atividade, qual seja, a percepção das transformações sociais e econômicas de tempos e espaços distintos, como a expansão marítima portuguesa, a colonização e a Inconfidência Mineira.

Do ponto de vista do conteúdo estão claras as discrepâncias em apresentar temáticas tão distintas como se fossem próximas. Metodologicamente, o problema é outro: os fins da atividade didática não estão explicitados para os alunos, tampouco são compreendidos pelos professores. Ou seja: ensinar história para quê? Quais conteúdos possibilitam esse aprendizado? Por que esses conteúdos e não outros?

No exemplo citado, a música fica a serviço de uma concepção de aprendizagem na qual professores e alunos são identificados como reprodutores do conhecimento, pois não há relações entre a atividade didática e o conhecimento histórico escolar que se pretende desenvolver (Leontiev, 1978).

Uma alternativa a esse processo é buscar sempre a consciência sobre as atividades desenvolvidas em sala de aula. O princípio de uma atividade didática consciente está baseado justamente no fato de que professores e alunos precisam ter a compreensão clara de o que, para que e por que se deve estudar o que se propõe (Leontiev, 1978).

Para nós, professores e pesquisadores do ensino de história, a busca da consciência sobre o nosso objeto de estudo deve ser uma constante (Fonseca, 2003). A consciência sobre o que ensinar não pode estar desvinculada da consciência de por que e como ensinar. Ao analisarmos as formas mais elaboradas de utilização da música nas práticas de ensino de história, verificamos que a busca por essa consciência se torna mais complexa, porém necessária. 
MÚSICA PARA CRIAR EMPATIA COM A HISTÓRIA... OU... "NÃO QUERO LHE FALAR, MEU GRANDE AMOR, DE COISAS QUE APRENDI NOS DISCOS...”

Em nossa tese de doutorado desenvolvemos análises sobre as dificuldades enfrentadas com a temática (Soares, 2008), bem como empreendemos a análise teórica de algumas atividades desenvolvidas com a utilização da música como recurso didático. $\mathrm{Na}$ medida em que avançamos nas pesquisas e na definição do referencial teórico, confirmamos a hipótese de que há uma linha muito tênue entre a música ser um aliado ou um desagregador no processo de produção do conhecimento histórico escolar.

A música pode ser um excelente aliado nos processos de ensino de história. Isso porque, como foi dito com exagero pelos Titãs, "desde os primórdios até hoje em dia, o homem ainda faz o que o macaco fazia...". ${ }^{5}$ A música é um artefato cultural que auxilia o ser humano a estabelecer relações com o meio. As formas e objetivos com que esse artefato foi e é utilizado ao longo de nossa trajetória histórica são variáveis em seus contextos históricos e sociais. No Brasil, a música é um dos objetos da cultura mais presentes no cotidiano da sociedade.

Assim é também com os alunos nas escolas. Diferentes pesquisas constatam que os alunos interagem entre si por música (Duarte, 2011; Soares, 2008). Entre adolescentes do fundamental II e ensino médio, a música define os grupos e as amizades. Os alunos estabelecem relações com a música e com os gêneros musicais independentemente da atuação do professor e da escola.

Para nós, esse é um aspecto fundamental a ser analisado, e que define sobremaneira o sucesso ou fracasso da utilização da música em uma atividade didática: compreender como os alunos interagem e se relacionam com as músicas e os gêneros musicais.

Ao aprofundarmos teoricamente essa questão, recorremos às análises seminais de Lev S. Vigotski sobre as relações que crianças e adolescentes estabelecem com o meio em que vivem, e, em que medida essa relação com o meio é significativa para os processos de desenvolvimento psíquico e cognitivo.

Na perspectiva de Vigotski, o meio é o contexto histórico e cultural no qual interagimos, e a formação de nossa personalidade não está dissociada desse contexto (Vigotski, 2010). Entende-se aqui o contexto histórico como as 
questões estruturais às quais estamos vinculados, tais como as instituições, as leis, o Estado, os processos econômicos, os modos de produção. Mas o meio é também o contexto cultural: o nosso cotidiano, a família, a religião, a escola, os colegas, os artefatos culturais, as músicas que ouvimos.

Embora a compreensão do meio seja fundamental, Vigotski discorda de forma contundente das vertentes deterministas e comportamentalistas que identificam o meio como definidor da personalidade e do desenvolvimento cognitivo (Vygotsky, 2000). Para esse autor, a análise do meio é importante, mas fundamental é a relação que os sujeitos estabelecem com o meio, ou seja, a vivência (Vigotski, 2010). A vivência é uma das categorias centrais da teoria vigotskiana (Solovieva, 2016).

A vivência é a relação: por vivência entende-se a relação que cada criança ou adolescente estabelece com o meio e com os artefatos culturais com os quais tem contato.

A vivência de uma situação qualquer, a vivência de um componente qualquer do meio determina qual influência essa situação ou esse meio exercerá na criança. Dessa forma, não é esse ou aquele elemento tomado independentemente da criança, mas, sim, o elemento interpretado pela vivência da criança que pode determinar sua influência no decorrer de seu desenvolvimento futuro. (Vigotski, 2010, p.683-684)

Com Vigotski verificamos que o meio é fundamental para o desenvolvimento dos indivíduos. No meio em que vivemos podemos ter mais ou menos acesso aos bens culturais, ao conhecimento científico ou ao patrimônio histórico. No entanto, o meio não determina nosso desenvolvimento psíquico. Este é determinado pela vivência, pela relação que estabelecemos com o meio.

A vivência pode ser assim exemplificada: o fato de que algumas crianças ouvem música erudita em casa não é um definidor de que irão ter apreço por esse gênero musical na adolescência ou na vida adulta. $\mathrm{O}$ apreço ou não, o gostar ou não gostar, irá depender da vivência: de como se sentem nessa relação com a música, das relações com os pais e irmãos nesses momentos, das lembranças suscitadas pelas músicas, enfim, do sentido que cada criança dá a esse objeto da cultura a partir da experiência vivida. Essa vivência pode ser diferente entre irmãos de faixas etárias diferentes: o irmão mais velho pode ter tido uma relação muito positiva com a música erudita, pois os pais sempre 
ouviram com ele e isso era algo positivo; com o segundo filho a relação poderá não ter sido a mesma, em virtude de problemas de saúde enfrentados pelos pais, por exemplo, cuja lembrança lhe traz certa tristeza; por fim, o terceiro filho pode não aceitar ouvir a música erudita porque sempre remete aos problemas que essa situação de saúde na família trouxeram.

A vivência é uma categoria fundamental para pensarmos aspectos da didática escolar. No nosso caso, a categoria vivência é importante, pois nos ajuda a interpretar quais são as relações que os estudantes têm com a música, e assim pensar prospectivamente nas práticas de ensino de história que utilizam as músicas como recurso didático, fonte e objeto de estudo.

Sabemos que a música constitui parte do cotidiano de diferentes grupos sociais em contextos históricos distintos. Não conhecemos grupos ou sociedades a-musicais. Somente para citar o caso brasileiro, são inúmeras as pesquisas historiográficas que demonstram a importância da música na formação da nossa sociedade. A música brasileira nos possibilitou relações interétnicas e de classe social desde o período colonial (Napolitano, 2005), foi utilizada para negar pressupostos hegemônicos do Estado (Paranhos, 2015), está integrada desde os anos 1970 à indústria do entretenimento, em suas sonâncias e dissonâncias (Hermeto, 2012).

Em nossa sociedade, as crianças têm contato com a música desde que nascem, tomam o primeiro banho e são amamentadas com canções para bebês, tradicionais ou não, que fazem parte de nosso repertório desde a tenra infância, permanecendo conosco ao longo da vida. Por meio da música começamos a receber nossos códigos de cultura, evidenciando o nosso processo de humanização (Pino, 2005). Isso significa que a vivência que temos com as músicas é qualitativamente diferente da que temos com outros objetos da cultura.

As músicas fazem parte de nossas experiências sensoriais mais profundas, de nossas lembranças, nossa memória, enfim, de nossas vivências. É preciso considerar esse aspecto ao elaborarmos atividades didáticas com música. Isso requer do professor a sensibilidade para compreender que essa fonte, objeto de estudo ou recurso didático, não pode ser inserida na sala de aula como se as interações subjetivas não interferissem na sua manipulação. Todos os alunos podem conhecer uma mesma música, mas a vivência de cada um com a música é diferente. Uma mesma música festiva, independentemente do gênero, pode significar para uns a festa e boas lembranças, para outros pode lembrar os dias 
em que os pais brigaram ou o dia em que um familiar ou amigo faleceu. A música está no meio, mas cada sujeito interage com ela de modo singular.

Este é, a nosso ver, uma das principais dificuldades em se utilizar as músicas nas aulas de história: a incompreensão de que a música é um artefato cultural que desperta nos alunos diferentes vivências, e que, portanto, a não compreensão da relação que os alunos têm com a música pode limitar as possibilidades de aprendizagem sobre as músicas, a linguagem musical e o conhecimento histórico ao qual se referem.

Nas aulas, a música deVe Ser Mais... OU... “ESTÁtuas E COFRes E PAREDES PINTADAS, NINGUÉM SABE O QUE ACONTECEU...”

Há um importante indicador do compasso que existe entre produção historiográfica e pesquisas sobre ensino de história no Brasil. Se, por um lado, a pesquisa historiográfica tem buscado na música um importante objeto de estudo e fonte de análise (Contier, 1998; Napolitano, 2005; Paranhos, 2015), por outro, pesquisadores do ensino de história têm investigado o uso da música como recurso didático, com o intuito de possibilitar para o contexto escolar algumas características da pesquisa historiográfica (Duarte, 2011; Hermeto, 2012). Nossa contribuição acrescenta outro elemento, embora não seja novo: a necessidade de se incorporar à vivência que os alunos têm com a música nos processos de produção do conhecimento histórico escolar.

Como vimos, a vivência está relacionada a aspectos objetivos e subjetivos. Objetivamente, os "gostos musicais" se definem a partir do acesso que as pessoas têm às músicas e aos gêneros musicais. É o meio que define se teremos acesso somente ao que é divulgado nas diferentes mídias, com suas engrenagens que fazem os ouvintes ouvirem "mais do mesmo", ou se teremos acesso às outras produções musicais, sem grande apelo midiático. Há que se considerar também nosso contato com a cultura musical de cunho regional ou religioso, como os sambas de roda, as modas de viola, as congadas, as folias de reis etc. Enfim, o meio define o acesso que temos a determinados gêneros musicais e suas músicas específicas. Subjetivamente, a vivência é um fenômeno individual e coletivo, ou seja, os "gostos musicais" são definidos pelo fato de que cada pessoa se relaciona com a música e com o gênero musical de forma única, 
pessoal. Concomitantemente, essa individualidade não existe fora do coletivo, fora da interação dos sujeitos com os grupos sociais com os quais interage.

Com esses princípios, defendemos que, ao considerar as vivências dos alunos nos processos de ensino com a utilização da música, é preciso identificar aspectos objetivos e subjetivos dessa vivência. $\mathrm{O}$ caráter objetivo está relacionado a "o que os alunos ouvem", aos seus "gostos" musicais, o que agrega musicalmente o maior número de alunos, quais as divergências "sonoras" existentes entre eles. O caráter subjetivo se relaciona a "como é a escuta" dos alunos, que tipo de interações são realizadas por meio da música, quais os inúmeros sentidos que a música tem no cotidiano dos alunos.

As diferenciações entre objetividade e subjetividade, materialidade e totalidade, também estão presentes na historiografia e implícitas às pesquisas sobre história e música ou história e ensino de história. Por exemplo, nos trabalhos de Contier (1998), Napolitano (2005) e Hermeto (2012), as propostas metodológicas de análise da música como fonte demonstram a necessidade de não apenas analisar letra e melodia, mas todo o processo de produção, circulação e consumo musical. Claro está, tanto para os historiadores quanto para os pesquisadores do ensino de história, que a música não se resume ao estudo da letra e da melodia no contexto de sua produção.

Em um dos primeiros trabalhos sobre a temática publicados no Brasil, Marcos Napolitano (1987) propõe a seguinte definição sobre a importância da música como documento sócio-histórico:

Totalidade e materialidade sonoras, que possuem uma sublinguagem que age no desejo, e uma linguagem que a constitui, e como tal deve ser analisada em sua totalidade e materialidade sonoras: linguagem, enfim, passível de leitura, e não desligada das influências da realidade social, o que permite a socialização desta leitura (resguardadas as marcas individuais). (Napolitano et al., 1987, p.181, grifo nosso)

Concordamos então com a definição de que a música como fonte não pode ser analisada apenas a partir de seus elementos objetivos, pois se existe uma linguagem que a constitui, há também uma sublinguagem, agindo no desejo daquele que interage com a música (Napolitano et al., 1987).

Ocorre que na proposta didática apresentada por Marcos Napolitano (1987; 2005), os aspectos subjetivos são considerados como se eles existissem apenas 
no passado, ou seja, a fruição da música não é disponibilizada aos alunos, mas estes devem interpretar como "pode ter sido" essa fruição no passado.

Isso também ocorre na proposta metodológica apresentada no importante trabalho de Miriam Hermeto (2012). A autora valoriza a "dimensão sensível" que se deve desenvolver para análise das obras musicais, reconhecendo que "a composição de uma canção sempre tem uma forte carga emocional e gera no ouvinte, via de regra, um impacto emocional" (Hermeto, 2012, p.148). Na proposta de Hermeto, a dimensão sensível é valorizada, mas nas propostas didáticas apresentadas não há espaço para a dimensão sensível dos alunos que ouvem e interagem com as músicas. Fica implícito então que a "forte carga emocional" está situada no passado, não se relaciona com as possíveis interpretações que os alunos fazem sobre as músicas.

Em alguns casos, as pesquisas desconsideram por completo as interações dos alunos. A pesquisa de Katia Abud (2005), por exemplo, ao apresentar uma proposta metodológica de análise da música Três Apitos, de Noel Rosa, em âmbito escolar, parte do interessante pressuposto de que a análise da música proporciona aos alunos a diferenciação entre conceitos cotidianos e conceitos históricos (Abud, 2005, p.313). Ocorre que, em sua proposta metodológica, não há espaço para a interpretação que os alunos têm em relação à música. $\mathrm{O}$ contexto de produção e circulação da obra está dado a priori pelo professor pesquisador. Assim, a música se torna fonte de análise, uma boa fonte, mas estéril, desprovida de sentimentos.

Para tentar entender outros aspectos sobre os usos das músicas nas aulas de história, a pesquisa desenvolvida por Milton Duarte (2011) levantou dados a partir do cotidiano escolar. Pela observação dos alunos e análise das aulas e de entrevistas com alunos e com a professora, Duarte (2011) concluiu que as músicas nas aulas de história são importantes por duas razões principais: possibilitam empatia entre docente e alunos, criando canais de diálogo sobre temas e situações variados, independentemente do conteúdo escolar; e as músicas são importantes suportes para a aprendizagem da história, servindo como suporte mnemônico para os conteúdos trabalhados em sala de aula.

Os dados apresentados por Milton Duarte (2011) reforçam a tese de que a música, em ambiente escolar, é importante aliado dos professores em busca de um ensino de história mais criativo e que se utilize de diferentes fontes e recursos didáticos. Porém, as conclusões de Duarte ainda nos remetem a uma 
dicotomia nesses processos: sabe-se que os alunos "gostam" de música, então levamos música para as aulas; no entanto, não buscamos vínculos entre as formas como os alunos ouvem as músicas e as possibilidades de interpretação da história que as músicas nos fornecem.

Nas práticas analisadas por Duarte (2011) os alunos ouviam música no pátio durante o intervalo, e a professora de história "deixava” que, uma vez por semana, os alunos levassem os seus CDs para a sala de aula. Criava-se empatia com a professora, o que é fundamental. Porém, as músicas de cunho "histórico" (sic) apresentadas nas aulas tinham objetividade explícita: facilitar a interpretação e memorização de determinados conteúdos.

O que temos identificado, em linhas gerais, é que nas pesquisas de ensino de história há consenso de que a música não é apenas uma boa fonte de análise, mas também um importante recurso didático para estimular e incentivar os alunos durante as aulas. Ocorre que, em muitas situações, tanto a cultura musical dos alunos quanto as relações de sentido que eles estabelecem com as músicas não são consideradas. É sobre esse aspecto da metodologia de ensino que trataremos no próximo item.

\section{MÚSICA PARA ENSINAR, APRENDER E PRODUZIR HISTÓRIA... OU... "Etelvina, ACERTEi No Milhar..."}

Nos estudos desenvolvidos no campo da psicologia pelo teórico Alexei Leontiev (1978) há uma imagem interessante, e popular, para nos alertar sobre as incoerências que as atividades didáticas podem apresentar. Sua assertiva é esta: "as melhores intenções que temos inculcado em nosso educando podem converter-se nele nessa classe de intenções, das que se diz: de boas intenções está pavimentado o caminho ao inferno" (Leontiev, 1978, p.185, trad. nossa). Com isso queremos afirmar que o ensino, ainda que bem orientado, não necessariamente possibilita aos alunos a aprendizagem. Entretanto, uma aprendizagem bem-sucedida não se desenvolve sem um processo de ensino bem orientado. Deixemos claro que estamos tratando aqui da educação escolar, e não de outros modelos de educação, como a familiar ou moral.

Mas qual a importância dessas afirmações para a análise das relações aqui desenvolvidas sobre música e ensino de história? Porque compreendemos ser necessário buscar sempre a consciência sobre o objeto de estudo (Leontiev, 
1978). Essa busca não é definida apenas pelo professor, que tem mais conhecimento e experiência que o aluno, mas também pelos meios de que o professor dispõe para despertar a consciência dos alunos sobre o objeto, ou seja, os métodos de ensino. A consciência não se caracteriza pela habilidade, memória, atenção ou reflexos psíquicos. A consciência sobre o objeto de estudo ocorre quando, na atividade didática, os fins e objetivos da atividade são compreendidos por professores e alunos (Leontiev, 1978). E isso nem sempre ocorre.

Em muitas situações, a consciência sobre os fins e objetivos de se ouvir uma música em sala de aula está bem definida pelo professor, mas não compreendida pelo aluno. Nessas situações, para os alunos, "O conteúdo que se percebe e o que se compreende não coincidem diretamente" (Leontiev, 1978, p.191, trad. nossa).

Por exemplo: o professor prepara um material para a análise da música Homenagem ao malandro, de Chico Buarque. ${ }^{6}$ Elabora boas perguntas para a análise da letra: sobre o contexto político em que a música foi composta, as relações entre o passado e presente, as concepções políticas do compositor, as metáforas a respeito das aparências. Suponhamos que, para "ajudar" no processo de interpretação e criar empatia, o professor solicite que os alunos ouçam a música. Que papel tem a audição da música no processo de análise da letra? Nenhum.

Vejamos: o fim e o objetivo da atividade eram a análise dos conteúdos e metáforas implícitas à letra, portanto, as ações que os alunos precisavam desenvolver deveriam estar vinculadas a este fim: ler e interpretar de acordo com as solicitações apresentadas pelo professor. Mas, ao solicitar a audição, insere-se outra ação que desvia, parcial ou totalmente, o aluno da atividade. Insere-se na atividade o estímulo a outros sentidos, e, portanto, a atividade inicial, que é interpretar a letra, sai do primeiro plano da consciência do aluno. Alguns alunos continuarão analisando a letra, mas irão prestar mais atenção nas rimas, nos instrumentos musicais ou na relação letra e melodia. Uns irão negar de forma explicita a "música chata do professor", enquanto outros farão a negação de forma silenciosa, direcionando seus pensamentos para outra situação externa à aula.

Nesse caso, "A suposição incorreta do ângulo psicológico consiste em que, quando no 'campo da consciência' do aluno aparece algum objeto, isso baste para que se tome consciência de tudo o que esse objeto contém realmente" 
(Leontiev, 1978, p.202, trad. nossa). Ou seja, na concepção tradicional da didática, bastaria possibilitar ao aluno uma poesia e uma música de Chico Buarque para que os alunos tivessem interesse nesse conteúdo. Na prática, não é isso que ocorre, pois...

Vimos que o 'processo da atenção', ou seja, o processo de tomada de consciência, não é um processo formal, mas rico em conteúdo e orientado a um fim, que está vinculado à ação interna. Por isso, o primeiro e principal questionamento com o qual devemos encarar a análise do material que examinamos é o seguinte: que ação, e orientada a que fim, deve assegurar? (Leontiev, 1978, p.202)

Ao afirmar que "a tomada de consciência não é um processo formal”, esse teórico postula que o processo não ocorre sem a participação do sujeito, nesse caso, o estudante. Assim, precisamos atentar cotidianamente para os efeitos das concepções didáticas do "toma lá, dá cá”, nas quais os professores não se preocupam em saber como os alunos se vinculam às atividades didáticas. A tomada de consciência sobre o estudo é um processo "rico em conteúdo e orientado a um fim". Aqui, aprender não é responder corretamente às questões ou fazer o que os professores solicitam. Aprender é estabelecer vínculos “internos” com o conteúdo, querer aprender, se interessar, voltar sua atenção para aquele conhecimento.

A tomada de consciência é uma "ação interna" do sujeito em relação ao conteúdo da atividade, ocorre quando o estudante tem claros para si os objetivos das ações que desenvolve. No caso que exemplificamos, os estudantes têm dificuldades em compreender os fins da atividade, portanto, de tomar consciência sobre o seu conteúdo.

Para pensar prospectivamente a partir desse mesmo exemplo, podemos sugerir que a ação de ouvir música seja orientada para um fim específico no âmbito da produção do conhecimento histórico. Para a utilização da música em sala de aula é fundamental que seus objetivos específicos sejam muito bem explicitados aos alunos.

Continuemos com o mesmo exemplo. Suponhamos que o professor tenha solicitado apenas a interpretação da letra, sem a audição da música. Tendo sucesso nessa atividade inicial, o professor, na aula seguinte, inicia uma conversa com os alunos sobre a música de Chico Buarque e a cultura musical dos alunos. Pode começar perguntando sobre os gêneros musicais que os alunos 
ouvem, e deixar os alunos falarem sobre isso. A aula pode caminhar para saber quem ouve samba, ou quem sabe quem é Chico Buarque, ou mesmo se algum aluno na sala já ouviu a música Homenagem ao malandro. Em determinado momento da aula, a proposta é lançada: "vamos ouvir a música”. O professor pede aos alunos que mudem a disposição das cadeiras, ou leva os alunos para outra sala, criando meios propícios para uma audição mais qualificada. Ao ouvir a música, solicita aos alunos atenção a questões específicas: sobre o gênero musical; se é apenas um samba ou se tem elementos de chorinho; sobre os instrumentos utilizados. Podem-se fazer duas ou três audições, cada qual com um objetivo específico.

A depender de como ocorreu a aula em que houve a audição, as possibilidades de continuidade do trabalho com a música podem ser diversas. Uma delas é instigar e desafiar os alunos a procurar outras músicas de Chico Buarque que utilizam metáforas para a compreensão da sociedade daquele período; outra possibilidade é delimitar o mesmo período histórico, mas instigar e desafiar os alunos para que tragam músicas de outros compositores com metáforas. ${ }^{8}$

Com tais mudanças, pensamos que "vê-se muito claramente quão notório é o efeito que se consegue ao criar interesses modificando a estrutura da atividade" (Leontiev, 1978, p.228, trad. nossa). Modificar a estrutura da atividade significa utilizar os mesmos recursos didáticos, mas transformando os objetivos e fins acerca dos conteúdos. Deixando de ser um objeto colateral à aula e passando a ser o objetivo e fim da atividade, modifica-se o interesse e a atenção dos alunos, e, portanto, possibilita-se a tomada de consciência sobre a música não apenas como recurso didático, mas como fonte e objeto para a produção do conhecimento histórico.

Quando ocorre uma mudança na estrutura da atividade (Leontiev, 1978, p.228), é possível despertar novos interesses e novas "necessidades" (Leontiev, 2001). Por exemplo: alguns alunos podem se sentir desafiados a confrontar o seu conhecimento com o do professor e levar as músicas que conhecem para comparar com as de Chico Buarque; outros alunos podem se sentir estimulados a conversar com os familiares sobre as músicas desse compositor, como já verificamos em pesquisas anteriores (Soares, 2008).

Do ponto de vista do desenvolvimento cognitivo, o que se modificou entre a primeira atividade proposta e a segunda? Entre a atividade na qual a audição 
da música era um conhecimento colateral e a atividade em que a audição inseriu a música como principal objeto do conhecimento?

Em suas pesquisas, Leontiev (s.d.; 1978; 2001) demonstra que ao modificar os vínculos dos alunos com a atividade, suas necessidades vão se transformando, exigindo novas estruturas cognitivas e levando-os a incorporar os motivos da atividade.

No nosso exemplo, podemos supor que quando os alunos estavam interpretando a letra, as necessidades de conhecimento deles estavam voltadas para o texto. Mas, quando o professor sugere a audição, muitas necessidades surgem, dispersando os vínculos criados entre os alunos e aquilo que estava estimulando a atividade. A incorporação do motivo da atividade ocorre quando os alunos tomam consciência de suas novas necessidades, que nos casos da educação escolar são despertadas pela forma como o professor propõe a conduz a atividade. Ao mudar a estrutura da atividade e inserir a música como objeto e fim do conhecimento, os alunos despertam para a necessidade de produção de um novo conhecimento sobre as músicas, um conhecimento histórico. Nesse caso, os fins da atividade não são formais, mas "fins que objetivamente eram já teóricos, cognoscitivos" (Leontiev, 1978, p.228, trad. nossa). Incentivados pelo professor, os alunos passam a elaborar questões de cunho teórico sobre a música e seu contexto histórico, possibilitando assim o desenvolvimento de capacidades cognitivas não consideradas anteriormente.

Esse tipo de modificação na estrutura da atividade não ocorre somente com a música, mas com qualquer atividade didática e seus respectivos materiais. Para tanto, é imprescindível que os fins e objetivos de cada ação em uma atividade didática estejam claros e bem definidos pelo professor, e que este consiga transmitir essa objetividade aos alunos. No entanto, a música, assim como os filmes, os videoclipes, os audiovisuais e as gravuras, incorporam elementos que, como vimos, podem facilitar ou dificultar os processos de ensino e de aprendizagem: as músicas lidam, inexoravelmente, com as sensações e os sentidos, e estabelecem vínculos estreitos com as vivências dos alunos.

É por essa razão que ao inserir a música como material e objeto de estudo, o professor coloca toda a sua intuição à prova. É preciso que o professor esteja atento à cultura musical dos alunos, que consiga modificar o "ambiente" da sala de aula quando for ouvir as músicas, que fique atento para identificar se os alunos estão "com os ouvidos disponíveis" para a audição. Isso é tanto mais 
difícil quanto mais avançamos no ensino fundamental II e ensino médio. Mas, quando isso ocorre, as possibilidades de um bom ensino e de uma boa aprendizagem são maiores.

Concluindo... OU... "LET ME TRY AgAin..."

Em recente pesquisa que desenvolvemos sobre o ensino de história em suas relações com a leitura e a escrita, ${ }^{9}$ elaboramos algumas atividades com música para verificar nossas hipóteses.

Ao longo do ano de 2015, dois discentes do curso de História da Universidade Federal de Alfenas (Unifal/MG) acompanharam as aulas de história de uma turma do $7^{\circ}$ ano do ensino fundamental II de uma escola pública da cidade de Alfenas. ${ }^{10}$ Embora os discentes, bem como a professora da turma, estivessem vinculados à pesquisa, solicitou-se que as atuações deles em sala de aula fossem semelhantes aos dos estagiários dos cursos de graduação em licenciatura: uma mescla de observação com intervenções pontuais e algumas regências.

Embora as músicas estivessem presentes em diversas atividades, analisaremos brevemente aqui uma atividade que teve a música como objeto central de análise: a audição de músicas eruditas que remetessem os alunos às temáticas sobre o período renascentista.

Aqui, utilizou-se uma estratégia que buscava vincular os alunos à atividade de ouvir as músicas. Os discentes e a professora tentaram criar um ambiente propício à audição das músicas, mudando a disposição dos móveis na sala, fazendo uma roda no chão, mudando o tom de voz e inserindo os alunos no clima da audição. Em um primeiro momento, como forma de inserir os participantes no objetivo da atividade, todos ouviram uma versão de Scarborough fair, ${ }^{11}$ na interpretação de Sarah Brightman. Posteriormente, a orientação era de que todos iriam ouvir dois exemplos de música erudita e, posteriormente, um exemplo de música "caipira”. Das músicas eruditas, a audição foi de um trecho de Toccata e fuga em D menor, de Bach, ${ }^{12}$ e da ária Lascia ch'io pianga, de Handel. ${ }^{13}$ A música caipira foi Amargurado, de Tião Carreiro e Pardinho”. ${ }^{14}$

O objetivo da atividade era demonstrar aos alunos que as composições musicais estão vinculadas ao contexto histórico em que foram produzidas, portanto, fruto de um tempo e espaço específicos. Não era o objetivo ter uma 
aula sobre a história da música erudita, mas sim, sobre a composição musical em diferentes contextos históricos. Nesse sentido, pretendíamos que as ações solicitadas estivessem explícitas aos alunos, e que estes entendessem os fins e objetivos da atividade.

Segundo um dos discentes, a atividade "contou com a participação de praticamente todos os alunos. Eles se envolveram bastante e gostaram muito de descrever as sensações das músicas mais antigas, bem como descrever as suas preferidas e comparar as diferenças entre elas" (Discente 1). Na avaliação de outro discente, "a maioria dos alunos se envolveu, mas cada grupo de alunos se portou de uma maneira, alguns falaram que não gostaram, outros dormiram... alguns fizeram perguntas do tipo 'na Idade Moderna as pessoas ouviam isso?"” (Discente 2).

É interessante verificar que apesar de a metodologia tentar inserir a todos, ainda houve resistências e negações, que a nosso ver ocorrem em função das poucas oportunidades que os alunos têm de conhecer e interagir com os fins e objetivos das atividades desenvolvidas em sala. Mesmo assim, um número significativo de alunos se inseriu na atividade. Ainda segundo os discentes, "os alunos na ocasião disseram se sentir na roça, num dia de domingo, comendo churrasco... e em relação às músicas renascentistas, eles diziam se sentir numa batalha ou indo para a guerra" (Discente 1).

Significativo é o fato de que os alunos tentaram estabelecer vínculos com as músicas, e de músicas que nunca tinham ouvido. O fato de Alfenas (MG) ser uma cidade pequena e que muitos alunos ou moram na "roça" ou a visitam com frequência, possibilitou que muitos estabelecessem vínculos afetivos com a música caipira. Ao analisar a música erudita, eles se lembraram dos filmes e dos elementos disponíveis na cultura midiática. Enfim, muitos alunos se inseriram na atividade, compreendendo sua finalidade.

Do ponto de vista da produção do conhecimento histórico escolar, o que consideramos importante é que os alunos tentaram dar explicações sobre as relações entre as músicas e seus contextos. Professora e discentes estimularam a audição com perguntas sobre o local em que a música foi composta, sobre quem ouvia essas músicas, para quem ela foi composta, e, sobre as sensações e "imagens" que as músicas traziam para os alunos. Mais do que respostas corretas, esperava-se produzir conhecimento histórico escolar e possibilitar desenvolvimento cognitivo naquele contexto escolar específico. O conteúdo 
prosseguiu naquilo que foi possível para professora, discentes e alunos. Mas aquele momento específico da audição tinha ficado objetivado para os participantes da aula.

Se formos rigorosos em termos históricos e historiográficos, engessando o currículo e as práticas sobre referenciais formais, diremos que a audição foi falha: os distintos contextos históricos não estavam explícitos e bem definidos, os alunos não conheceram o contexto das produções, os compositores, as letras e partituras não foram analisadas. Mas naquela turma de $7^{\circ}$ ano, com alunos na faixa de 11 e 12 anos, desprestigiados e em uma escola pública também desprestigiada, os resultados foram cognitivamente satisfatórios, pois ouviram o que não costumam ouvir, buscaram interpretar sensações, comparar contextos de produção e, principalmente, começar a compreender que a música é também resultado de um processo histórico.

Para Vigotski, ensinar é disponibilizar uma aprendizagem que possibilite aos alunos o desenvolvimento pessoal, social e cognitivo (Vigotski, 2001a). Estamos na defesa de um ensino de história que possibilite aos alunos esse desenvolvimento. Como as demais disciplinas escolares, a história deve estar a serviço dos processos de elevação das capacidades humanas de crianças e adolescentes. Não podemos aceitar que as crianças oriundas das classes sociais desfavorecidas estejam alijadas dos processos de produção do conhecimento (Libâneo, 2012), pois em nossa concepção, uma boa educação escolar não apenas reproduz ou transmite conhecimento, mas, sobremaneira, produz conhecimento.

O conhecimento histórico escolar deve possibilitar às crianças e adolescentes a desnaturalização da vida e do cotidiano. Isso se torna possível na medida em que os alunos são incentivados a ter acesso ao conhecimento que não têm. Mas no cotidiano é que se localizam as sensações e os sentimentos dos alunos, a sua vivência. Nesse sentido, a cultura cotidiana pode ser uma das chaves que nos permita inserir os alunos na história da humanidade.

Ouvir e interpretar exigem capacidades cognitivas elevadas, aquilo que Vigotski definiu como funções psicológicas superiores (Vygotsky, 2000). Porém, assim como é possível reprimir o desenvolvimento dessas funções, com "decorebas" e interpretações predefinidas, também é possível desafiar os alunos e suas capacidades. Nessa concepção, ensinar história tem dois objetivos básicos: 
inserir os alunos no contexto histórico da humanidade e possibilitar a eles desenvolvimento e cognitivo.

\section{REFERÊNCIAS}

ABUD, Katia M. Registro e representação do cotidiano: a música popular na aula de história. Cadernos Cedes, Campinas, v.25, n.67, p.309-317, set./dez. 2005.

BRASIL: Secretaria de Educação Fundamental. Parâmetros Curriculares Nacionais/ História. Brasília: MEC/SEF, 1998.

CONTIER, Arnaldo D. Edu Lobo e Carlos Lyra: o Nacional e o Popular na Canção de Protesto (Os Anos 60). Revista Brasileira de História, São Paulo, v.18, n.35, p.13-52, 1998. Disponível em: http://www.scielo.br/scielo.php?script=sci_ arttext\&pid=S0102-01881998000100002\&lng=pt\&nrm=iso.

DUARTE, Milton D. F. A música e a construção do conhecimento histórico em aula. Tese (Doutorado em Educação) - Faculdade de Educação, Universidade de São Paulo (USP). São Paulo, 2011.

FONSECA, Selva G. Didática e prática de ensino de história. Campinas: Papirus, 2003.

HERMETO, Miriam. Canção popular brasileira e ensino de história: palavras, sons e tantos sentidos. Belo Horizonte: Autêntica, 2012.

LEONTIEV, Alexei N. Actividad, conciencia y personalidad. Buenos Aires: Ediciones Ciencias del hombre, 1978.

. Uma contribuição à teoria do desenvolvimento da psique infantil. In: VYGOTSKY, Lev S. (et al.) Linguagem, desenvolvimento e aprendizagem. Trad. Maria da Penha Villalobos. 8.ed. São Paulo: Ícone, 2001. p.59-83.

LIBÂNEO, José Carlos. O dualismo perverso da escola pública brasileira: escola do conhecimento para os ricos, escola do acolhimento social para os pobres. Educação e Pesquisa, São Paulo, v.38, n.1, p.13-28, 2012. Disponível em: http://www. scielo.br/scielo.php?script=sci_arttext\&pid=S1517-97022012000100002\&lng=pt \&nrm=iso.

MELLO, Sueli A. Ensinar e aprender a linguagem escrita na perspectiva histórico-cultural. Psicologia Política, São Paulo, v.10, n.20, p.29-343. 2010. Disponível em: http://pepsic.bvsalud.org/scielo.php?script=sci_arttext\&pid=S1519-549X2010000 200011\&lng=pt\&nrm=iso.

NAPOLITANO, Marcos. História \& música: história cultural da música popular. Belo Horizonte: Autêntica, 2005.

. (et al.) Linguagem e canção: uma proposta para o ensino de história. Revista Brasileira de História, São Paulo, v.7, n.13, p.177-188, 1987. 
PARANHOS, Adalberto. Os desafinados: sambas e bambas no "Estado Novo". São Paulo: Intermeios; CNPq; Fapemig, 2015.

PINO, Angel. As marcas do humano: às origens da constituição cultural da criança na perspectiva de Lev S. Vigotski. São Paulo: Cortez, 2005.

PUENTES, Roberto V.; LONGAREZI, Andréa M. Escola e didática desenvolvimental: seu campo conceitual na tradição da teoria histórico-cultural. Educação em Revista, Belo Horizonte, v.29, n.1, p.247-271, 2013. Disponível em: http://www.scielo. br/scielo.php?script=sci_arttext\&pid=S0102-46982013000100012\&lng=pt\&nrm= iso.

.; LONGAREZI, Andréa M. (Org.) Ensino desenvolvimental: vida, pensamento e obra dos principais representantes russos. Uberlândia: Edufu, 2013.

SOARES, Olavo P. A atividade de ensino de história: processo de formação de professores e alunos. Araraquara, SP: Junqueira \& Marin, 2008.

. O ensino de história nos anos iniciais e a formação dos professores. In: FONSECA, Selva G. (Org.) Ensinar e aprender História: formação, saberes e práticas educativas. Campinas: Átomo e Alínea, 2009. p.127-147.

SOLOVIEVA, Yulia. La formación de las funciones psicológicas en el desarrollo humano. In: BARBOSA, Maria V.; MILLER, Stela; MELLO, Sueli A. (Org.) Teoria histórico-cultural: questões fundamentais para a educação escolar. Marília, SP: Oficina Universitária; Cultura Acadêmica, 2016. p.37-56.

VIGOTSKI, Lev S. Aprendizagem e desenvolvimento intelectual na idade escolar. In: . (et al.) Linguagem, desenvolvimento e aprendizagem. Trad. Maria da Penha Villalobos. 8.ed. São Paulo: Ícone, 2001a. p.103-117.

. A construção do pensamento e da linguagem. Trad. Paulo Bezerra. São Paulo: Martins Fontes, 2001b.

Quarta aula: a questão do meio na pedologia. Psicologia USP, São Paulo. v.21, n.4, p.681-701, 2010. Disponível em: http://www.scielo.br/scielo. php?script=sci_arttext\&pid=S0103-65642010000400003\&lng=pt\&nrm=iso.

VYGOSTKY, Lev S. Génesis de las funciones psíquicas superiores. In: Obras escogidas III. Madrid: Visor, 2000. p.139-168.

\section{NOTAS}

${ }^{1} \mathrm{O}$ projeto intitulado "Leitura, escrita e interpretação da história com as crianças das escolas públicas" recebeu financiamento do convênio Fapemig/Capes mediante Edital 13/2012.

${ }^{2}$ Trata-se do Grupo de Pesquisa "Implicações pedagógicas da teoria histórico-cultural", da Unesp/Marília. 
${ }^{3}$ http://proportoseguro.blogspot.com.br/2008/12/msica-do-descobrimento-do-brasil. html.

${ }^{4}$ Usarei neste artigo a expressão genérica "atividade didática" por entender que não há espaço suficiente para discorrer sobre a "atividade de ensino". Para esse debate, ver nossa pesquisa de Doutorado (SOARES, 2008).

${ }^{5}$ Trecho da letra da música Homem Primata, de autoria de Sérgio Britto, Nando Reis, Marcelo Fromer e Ciro Pessoa. Disponível em: https://www.youtube.com/ watch?v=bswaluyQe8s.

${ }^{6}$ Disponível em: https://www.youtube.com/watch?v=vRyjAUk9CIU.

${ }^{7}$ VIGOTSKI (2000) explica que o desenvolvimento psicológico e cognitivo é sempre uma "ação interna" do sujeito. No entanto, "toda función psíquica superior fue externa por haber sido social antes que interna" (VIGOTSKI, 2000, p.150). As "ações internas" somente ocorrem após o contato com o meio, com a cultura.

${ }^{8}$ Uma atividade didática semelhante a essa foi analisada em nossa tese de doutorado (SOARES, 2008). No mesmo trabalho, há outra atividade com música que foi analisada na perspectiva da teoria da atividade.

${ }^{9}$ O projeto intitulado "Leitura, escrita e interpretação da história com as crianças das escolas públicas".

${ }^{10}$ Pesquisa devidamente aprovada pelo CEP/Conep com Parecer de no 1.366.209.

${ }^{11}$ Disponível em: https://www.youtube.com/watch?v=cgF-Jjxrp0s.

${ }^{12}$ Disponível em: https://www.youtube.com/watch?v=sYNLIdDl5v4.

${ }^{13}$ Disponível em: https://www.youtube.com/watch?v=HWD8d_YL30o.

${ }^{14}$ Disponível em: https://www.youtube.com/watch?v=XPMb2Qir4nA.

Artigo recebido em 16 de novembro de 2016. Aprovado em 3 de fevereiro de 2017. 